\title{
A análise da escola das estruturas sociais de acumulação sobre a economia dos Estados Unidos entre o pós-guerra e o início do século XXI ${ }^{1}$
}

\author{
Amanda Mayara da Silva Bento* \\ Marcelo Soares Bandeira de Mello Filho**
}

\begin{abstract}
Resumo
O objetivo principal do trabalho é apresentar a explicação da escola das estruturas sociais de acumulação (Eesa) para as transformações do capitalismo estadunidense ocorridas entre o pós-guerra e o início do século XXI. De acordo com a abordagem, a estrutura social de acumulação do pós-guerra, construída no contexto geopolítico da Guerra Fria, foi caracterizada por acordos entre os trabalhadores e os capitalistas e entre esses últimos e os cidadãos. Tais arranjos institucionais possibilitaram taxas de crescimento elevadas e significativos ganhos de salário real. A abordagem teve alguma dificuldade em compreender o tipo de capitalismo predominante nos Estados Unidos depois da estagflação da década de 1970 e teve que alterar o significado do seu conceito principal para analisar o capitalismo neoliberal.
\end{abstract}

Palavras-chave: Escola das estruturas sociais de acumulação. História econômica dos Estados Unidos. Neoliberalismo.

* Graduada em Ciências Econômicas pela Universidade Federal de São João Del-Rei (UFSJ). E-mail: mandamayara@hotmail.com

** Professor adjunto do Departamento de Ciências Econômicas da UFSJ. E-mail: marcelosbmf@gmail. com 


\section{Introdução}

O texto busca compreender a história econômica dos Estados Unidos, desde o pós-guerra, do ponto de vista da escola das estruturas sociais de acumulação (Eesa). A Eesa é uma abordagem oriunda da economia política radical americana e surgiu, a partir de 1978, procurando explicar o funcionamento do capitalismo de um ponto de vista histórico e realista, diferentemente das abordagens então predominantes. ${ }^{2}$ A Eesa tem como principais influências os pensamentos marxista, keynesiano e institucionalista, relacionando a teoria geral do capitalismo abordada por Marx e Keynes com os âmbitos histórico e empírico de cada período do capitalismo.

A Eesa defende o contexto histórico como essencial para a análise da sociedade, além da necessidade de entender a importância das instituições de um espaço econômico (de modo geral, o espaço nacional). Este estudo mostra que, do ponto de vista da Eesa, a economia não funciona somente com base na suposta racionalidade calculista e nas forças autorreguladoras do mercado. Existem outros fatores importantes para o funcionamento da economia, como as instituições (costumes, leis, regras, mecanismos de proteção social, etc.), essenciais para o funcionamento de uma sociedade. Segundo a definição mais utilizada pela escola, comentada ao longo do artigo, uma estrutura social de acumulação é um conjunto de instituições que garante crescimento rápido e estável por um período relativamente longo de tempo. A construção e a decadência de uma estrutura social de acumulação marcam uma etapa do capitalismo.

O objetivo principal do trabalho é apresentar a explicação da Eesa para as transformações do capitalismo estadunidense ocorridas entre o pós-guerra e o início do século XXI. De acordo com a abordagem, a estrutura social de acumulação do pós-guerra, construída no contexto geopolítico da Guerra Fria, foi caracterizada por acordos entre os trabalhadores e os capitalistas e entre esses últimos e os cidadãos. Ainda segundo a abordagem, tanto no âmbito nacional estadunidense quanto no plano internacional, a concorrência intercapitalista era restrita, especialmente em virtude da maior competitividade das corporações americanas vis-à-vis com as empresas europeias e japonesas.

A Eesa é similar a outras abordagens, de modo geral identificadas com a heterodoxia do pensamento econômico, que surgiram ou se revitalizaram da década de 1970 em diante, enfatizando a centralidade das instituições para a compreensão da realidade econômica. Entre tais abordagens, destacam-se o institucionalismo original, a nova economia institucional, a escola francesa da regulação, a abordagem neoschumpeteriana e a escola austríaca, que são relativamente conhecidas pelo 
público brasileiro. ${ }^{3}$ Infelizmente, a Eesa ainda não foi objeto de muitos estudos no Brasil. O presente artigo tem como objetivo secundário contribuir para que a escola seja mais conhecida pelo público lusófono e pressupõe que as contribuições da abordagem acerca do entendimento das instituições fundamentais do capitalismo estadunidense, tanto no período do pós-guerra quanto nas últimas década do século XX e no início do século XXI, são relevantes para a compreensão das mudanças históricas do capitalismo e para a investigação da economia contemporânea.

Para que o objetivo principal do trabalho seja cumprido, o argumento está estruturado da maneira descrita a seguir. $\mathrm{O}$ segundo item apresenta elementos para a compreensão do contexto histórico e do surgimento dos conceitos básicos da Eesa. Na terceira parte, é analisado um dos períodos mais importantes da economia estadunidense, a estrutura social de acumulação do pós-guerra, que teria durado entre o final da década de 1940 e meados da década de 1970. A quarta seção mostra a evolução da teoria diante do comportamento do capitalismo contemporâneo, chamado de estrutura social de acumulação neoliberal. A quinta parte trata de insuficiências teóricas e de perspectivas da abordagem sobre o capitalismo estadunidense atual. A última parte destina-se exclusivamente às considerações finais. ${ }^{4}$

\section{Escola das estruturas sociais de acumulação}

Nos Estados Unidos da década de 1960, ao mesmo tempo em que ganhavam força os movimentos feminista, estudantil, contra a Guerra do Vietnã, a favor dos Direitos Civis (Civil Rights), entre outros movimentos que formavam a Nova Esquerda (New Left), crescia o interesse acadêmico pela compreensão dos problemas - como o racismo, o sexismo e o imperialismo - contra os quais tais movimentos lutavam. No ambiente acadêmico de economia, alguns estudantes e professores, entre os quais se destacam Samuel Bowles, Barry Bluestone, Gene Coyle, Herbert Gintis, Arthur MacEwan, John Pool, Michael Reich, Tom Weisskopf e Howard Wachtel, fundaram em 1968 a Union for Radical Political Economics (URPE) e, no ano seguinte, a Review of Radical Political Economics. Em sua criação, a URPE teve o propósito de desenvolver uma interdisciplinaridade na economia, capaz de unir e discutir abordagens de economia, ciência política, sociologia e psicologia que, no ambiente acadêmico ortodoxo em economia, eram assuntos tratados em disciplinas separadas. Entre os temas pesquisados pela economia política radical, estão gênero, pobreza, desigualdade, racismo, educação, imperialismo, desemprego e sindicalismo. Para compreender tais fenômenos, os autores radicais retomavam conceitos de Marx, Keynes, Veblen e outros autores associados ao pensamento 
heterodoxo em economia (LEE, 2009; EDWARDS; REICH; WEISSKOPF, 1986; MELLO FILHO, 2016).

A partir da década de 1970, uma parcela dos economistas radicais americanos direcionou suas pesquisas para o entendimento da crise de estagflação que atingia a economia estadunidense. Nesse contexto, surgiu a abordagem em termos de estruturas sociais de acumulação, tendo como alguns dos desenvolvedores David Gordon, Michael Reich, Thomas Weisskopf, Richard Edwards, Samuel Bowles, David Kotz, Victor Lippit e Terrence McDonough. O foco principal das obras da Eesa são as análises macroeconômicas e histórico-institucionais, com ênfase nos Estados Unidos.

Para a Eesa, o comportamento normal de importantes variáveis macroeconômicas, como taxa de lucro, salário real, taxa de crescimento e taxa de desemprego, está associado ao funcionamento de instituições. David Gordon $(1978,1980)$ foi o autor pioneiro no estabelecimento de um conceito que procurava apreender as mudanças de longo prazo no comportamento macroeconômico com base em instituições, transformações tecnológicas e no conflito social, o conceito de estruturas sociais de acumulação. Este teve, nas origens da teoria, uma estreita relação com as ondas longas do capitalismo, também conhecidas como ciclos de Kondratiev. Nos trabalhos pioneiros de Gordon (1978, 1980), uma estrutura social de acumulação delimita ciclos econômicos de longa duração que condicionam períodos de crescimento e crise, liderados por investimentos massivos em infraestrutura que, por sua vez, seriam decorrentes de mudanças institucionais. As ondas longas do capitalismo perdurariam por cerca de cinquenta ou sessenta anos.

Ao longo do tempo, a Eesa deixou de lado a preocupação com a periodicidade das mudanças de longo prazo do capitalismo e enfatizou que uma estrutura social de acumulação é um conjunto de instituições que promove o crescimento rápido e estável por um longo período de tempo. A construção e o declínio de uma estrutura social de acumulação marcariam uma etapa do capitalismo. Além disso, o conceito possibilitaria a mediação entre a análise de Marx e o entendimento das variáveis econômicas tradicionais. Nesse sentido, Gordon, Edwards, Reich argumentam que:

[...] um nível intermediário de análise, focado na lógica das ondas longas e das etapas do capitalismo, é necessário para a compreensão do desenvolvimento capitalista. Esse nível de análise intermediário procura complementar tanto a análise abstrata e tradicional de Marx do desenvolvimento capitalista quanto a análise mais recente e concreta da vida cotidiana (1982, p. 22, tradução nossa). ${ }^{5}$

Depois de funcionar bem por certo tempo, as contradições inerentes às instituições fazem com que elas não consigam mais dar suporte para uma rápida 
acumulação de capital, e, a partir daí, surgem as instabilidades econômica e social, levando consequentemente às crises. Quando há o processo de colapso das instituições, começa a busca pela criação de uma nova estrutura social de acumulação, para promover novamente a acumulação de capital e o rápido crescimento.

Instituições, para os economistas radicais, seguindo o passo do institucionalismo original, não são o mesmo que organizações, mas podem ser leis, rotinas, hábitos e costumes de uma sociedade. Também são construções sociais mediadas por elementos políticos, ideológicos e culturais. Para McDonough (2006), as instituições variam de acordo com os períodos históricos que essas sociedades atravessam. Isso justifica o fato de os comportamentos econômico e social não serem iguais em todos os lugares e não funcionarem sempre da mesma maneira, pois são altamente influenciados pelas instituições, distintas conforme o espaço geográfico e o tempo histórico.

McDonough (2006) e Lippit (2010) afirmam que a integridade de uma estrutura social de acumulação se dá pelas inter-relações entre seus componentes, ou seja, pela interdependência e pela sobredeterminação das próprias instituições. Além disso, tanto o período de expansão econômica condicionada à estrutura social de acumulação quanto o período posterior de crise, que desintegra essa estrutura, tendem a ser longos. Isso ocorre pelo fato de as inter-relações entre os componentes da sociedade e a economia tenderem a ser relativamente fortes e, portanto, duradouras e de difíceis destruição e construção. A alternância entre esses longos períodos de rápido crescimento e épocas de crescimento baixo ou ausente forma, segundo a escola, as mudanças de longo prazo do capitalismo, explicadas pela construção e pela decadência de uma estrutura social de acumulação.

\section{A estrutura social de acumulação do pós-guerra}

Uma maneira clara de compreender o arcabouço teórico da Eesa é analisando a economia dos Estados Unidos no período pós-Segunda Guerra. As duas principais obras da Eesa que tratam do assunto são os livros Beyond the waste land (1984) e After the waste land (1990), de Samuel Bowles, David M. Gordon e Thomas E. Weisskopf. As duas obras, além de algumas publicações mais recentes, são as referências mais destacadas na presente seção. $O$ segundo livro é uma atualização do anterior, tendo cerca de metade de seu conteúdo idêntico ao livro de 1984 . As obras descrevem o que é chamado pelos autores em After the waste land de "estrutura social de acumulação do pós-guerra" (the postwar social structure of accumulation) e caracterizam esse período da economia estadunidense como uma

Teoria e Evidência Econômica - a. 24, n. 50, p. 26-50, jan./jun. 2018 
etapa do capitalismo composta por quatro principais instituições, que teriam sido responsáveis pelo sucesso econômico: "pax americana", "acordo capital-trabalho", "acordo capitalistas-cidadãos" e "contenção da rivalidade intercapitalista". ${ }^{6}$ Além dessas quatro instituições, Lippit (2010, p. 48-52) inclui o "sistema financeiro" como uma quinta estrutura fundamental para a compreensão do capitalismo americano do pós-guerra. É importante destacar que essas instituições não surgiram todas simultaneamente, elas foram sendo lentamente construídas, desde a década de 1930 , e funcionaram adequadamente até o começo da década de 1970.7

De acordo com a abordagem, a estrutura social de acumulação do pós-guerra possibilitou que a economia estadunidense apresentasse, em média, as maiores taxas de crescimento econômico da história moderna do país. A Tabela 1, a seguir, ilustra as elevadas taxas de crescimento entre as décadas de 1940 e 1970, em comparação com as décadas de 1980, 1990 e a primeira década do século XXI.

Tabela 1 - Taxa média de crescimento do produto interno bruto (PIB) real dos EUA entre 1930-2009

\begin{tabular}{c|c}
\hline Período & Média de crescimento \\
\hline $1930-1939$ & 1.3 \\
$1940-1949$ & 6.0 \\
$1950-1959$ & 4.3 \\
$1960-1969$ & 4.5 \\
$1970-1979$ & 3.2 \\
$1980-1989$ & 3.2 \\
$1990-1999$ & 3.2 \\
$2000-2009$ & 1.8 \\
\hline
\end{tabular}

Fonte: baseada nos dados apresentados por Bureau of Economic Analysis. ${ }^{8}$

A abordagem utilizada pela escola evita que o sistema econômico seja compreendido com base em aspectos isolados do todo. Desse modo, a explicação do sucesso estadunidense no período não é calcada apenas na maior presença do Estado na economia, nem no poder militar dos Estados Unidos ou na maior organização dos trabalhadores:

Muitos analistas simplificam as características desse novo sistema de poder corporativo, enfatizando uma ou outra dimensão isolada da transformação. Alguns enfatizam o papel muito maior do governo, chamando-o de "Estado de bem-estar social" ou de "economia mista". Outros focam nos seus aspectos internacionais, concentrando no século americano ou nas suas relações "neoimperialistas". Outros apontaram para o crescimento dos sindicatos industriais como seu aspecto distintivo (BOWLES; GORDON; WEISSKOPF, 1984, p. 63; 1990 , p. 48 , tradução nossa). ${ }^{9}$ 
De acordo com os autores, é o funcionamento conjunto da estrutura institucional do período que possibilita o elevado crescimento econômico. Para melhor entendimento da estrutura social de acumulação do pós-guerra, é mostrado na sequência como a Eesa compreende as instituições-chave do período.

A primeira instituição destacada é a "pax americana" (BOWLES; GORDON; WEISSKOPF, 1984, p. 65-66; 1990, p. 49-50; LIPPIT, 2010, p. 50) ou "dominância internacional estadunidense e ideologia da Guerra Fria" (MCDONOUGH, 1994, p. 117-118). Ela se caracteriza pelos poderes econômico e militar dominantes dos Estados Unidos no plano internacional. Um dos principais componentes que fazem parte da "pax americana" são as instituições construídas a partir do acordo de Bretton Woods, de 1944, que promoveu mecanismos de integração internacional e proporcionou aos EUA grande influência sobre a economia mundial, por meio da utilização do dólar como moeda internacional e por meio de organizações, como o Fundo Monetário Internacional e o Banco Mundial, sediadas em Washington.

O domínio dos Estados Unidos também foi caracterizado por atos hostis do governo, para garantir os interesses das grandes empresas privadas do país. Entre os acontecimentos, estão os golpes de Estado, promovidos pela Central Intelligence Agency, que derrubaram líderes internacionais que ameaçaram contrariar de alguma forma os objetivos privados da economia norte-americana. O poder militar dos Estados Unidos conseguiu derrubar o primeiro ministro iraniano Mohammed Mossadegh, no ano de 1953, após o governo Mossadegh nacionalizar a Companhia de Petróleo Anglo-Iraniana. Além disso, um ano depois, houve a derrubada do presidente da Guatemala Jacobo Arbenz, eleito democraticamente, que foi retirado de seu cargo após tentar realizar uma reforma agrária que afetaria a United Fruit Company. Esses atos contribuíram também com o fim definitivo do isolacionismo característico do período entreguerras (BOWLES; GORDON; WEISSKOPF, 1984, p. $66-67 ; 1990$, p. 50-51).

Outro importante componente da pax americana foi o Plano Marshall, que proporcionou melhora no desenvolvimento da Europa, além de promover financiamento internacional em troca da obtenção de privilégios para os Estados Unidos em mercados nacionais e em fontes de matérias-primas. O período que sucedeu a Segunda Guerra Mundial foi responsável também pela relativa abertura do mercado mundial, que expandiu o comércio internacional e deu maior mobilidade ao capital. A Guerra Fria justificou a ampliação dos gastos militares e a formação de consenso em torno de um inimigo comum (BOWLES; GORDON; WEISSKOPF, 1984, p. 68-69; 1990, p. 51-52; MCDONOUGH, 1994, p. 117-118).

O "acordo capital-trabalho" é caracterizado por um conjunto de benefícios, ainda que modestos, no âmbito do mundo do trabalho, após a Segunda Guerra Mundial. As conquistas da classe trabalhadora se deveram a reivindicações e à 
organização de greves e paralisações. Bowles, Gordon e Weisskopf (1989, 1990) apontam alguns indicadores do poder relativo da classe trabalhadora. Um desses indicadores aparece no Gráfico 1, a seguir, que mostra o número de paralisações envolvendo mil ou mais trabalhadores entre 1947 e 2016. Entre 1950 e 1975, ocorreram, em média, mais de 317 paralisações por ano. Já, entre 1990 e 2015, a média foi inferior a 25 paralisações por ano.

A partir da mobilização para a Segunda Guerra Mundial, os sindicatos se fortaleceram e conseguiram aprimorar as condições de trabalho e a proteção trabalhista. Desse modo, a classe trabalhadora, até então relativamente frágil, pôde começar a compartilhar da prosperidade capitalista. Alguns dos principais marcos do "acordo capital-trabalho" foram o National Labor Relations Act, de 1935, que garantia direito à sindicalização e à greve, e a legislação Taft-Hartley, de 1947, que restringia a capacidade de atuação política dos sindicatos e proibia que esses fossem liderados por radicais.

Na prática, a legislação e os convênios coletivos possibilitavam que os trabalhadores sindicalizados obtivessem expressivos ganhos salariais reais em troca da subordinação dos sindicatos ao Partido Democrata, da burocratização da atividade sindical e do controle dos empresários em relação a produção, investimento, local de trabalho e marketing (BOWLES; GORDON; WEISSKOPF, 1984, p. 70-75; 1990, p. 53-57; MCDONOUGH, 1994, p. 119-120).

Gráfico 1 - Paralisações envolvendo 1000 ou mais trabalhadores, EUA (1947-2016)

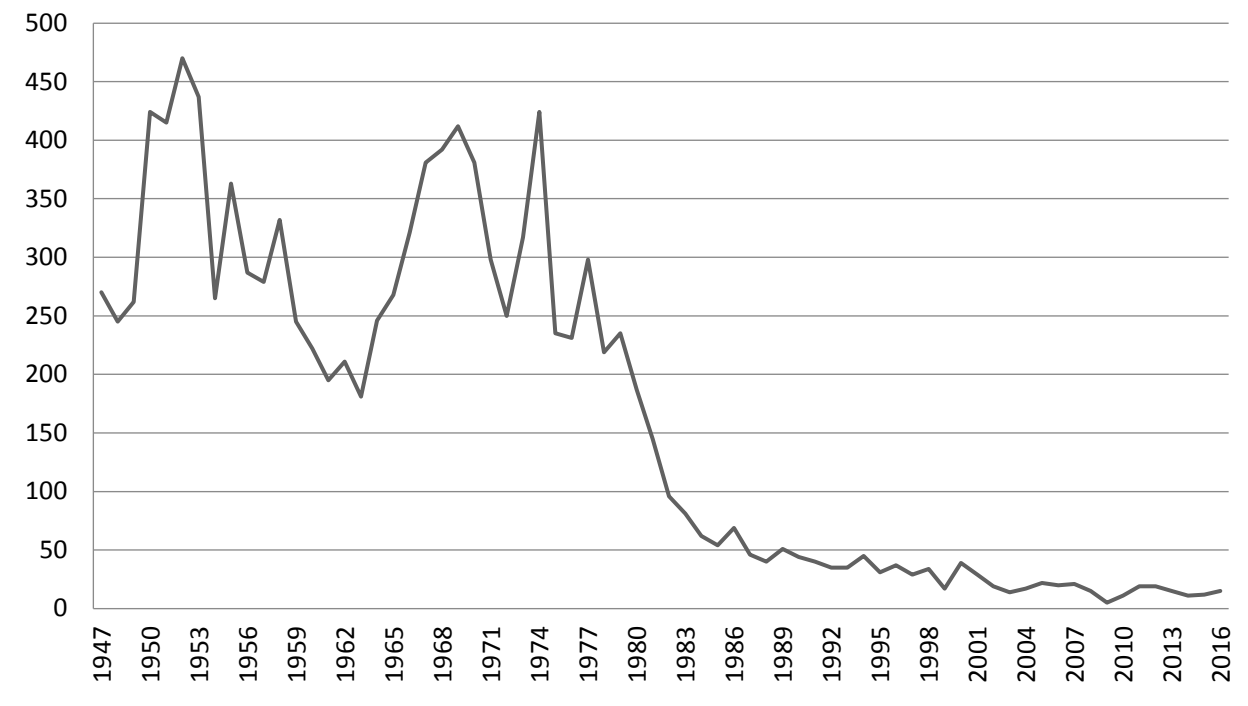

Fonte: baseado nos dados apresentados por Bureau of Labor Statistics. ${ }^{10}$ 
O "acordo capital-trabalho" beneficiava os trabalhadores sindicalizados, deixando, consequentemente, de lado os demais trabalhadores. Isso proporcionou uma importante segmentação da classe trabalhadora, entre os trabalhadores homens brancos (que tinham acesso a mais direitos e melhores ganhos salariais) e os trabalhadores negros e as trabalhadoras em geral (que desempenhavam papéis subordinados nas firmas e obtinham menor remuneração) (GORDON; EDWARDS; REICH, 1982; MCDONOUGH, 1994, p. 119-120).

O Gráfico 2, a seguir, indica dois fenômenos destacados pela Eesa. O primeiro fenômeno é o crescimento do salário real, entre o final dos anos 1940 e meados da década de 1960, acompanhando o avanço da produtividade, fenômeno explicado justamente pelo poder relativo da classe trabalhadora. Essa tendência predominou até a década de 1970, na qual o poder capitalista começa se sobressair novamente, e a competição, no âmbito da produção, começa a beneficiar muito mais os capitalistas. A grande mudança na distribuição dos ganhos de produtividade se dá pelo declínio do "acordo capital-trabalho", uma das marcas da crise da estrutura social de acumulação do pós-guerra. O segundo fenômeno importante que fica claro no Gráfico 2 é o declínio do crescimento da produtividade. Enquanto a produtividade dobrou em cerca de 20 anos, entre 1947 e 1968, ela só iria dobrar novamente cerca de 35 anos depois, em 2003.

A terceira instituição destacada pela abordagem, o "acordo capitalistas-cidadãos", começou a ser esboçada a partir do New Deal, de Roosevelt, conjunto de medidas que visava a superar a Grande Depressão por meio de intervenção pública moderada na economia. A instituição concentrou-se nos gastos públicos como estratégia do governo para promover os bem-estares social e privado. Dessa forma, os objetivos seriam: pensar na redução da instabilidade econômica no âmbito macro, aumentar os gastos do governo em educação, infraestrutura e outros investimentos (com o intuito de reaquecer o setor privado), garantir uma rede de proteção social, por meio de políticas como seguro desemprego e aprimoramento das condições de saúde e educação. Essa estratégia foi pensada para ajudar tanto o setor privado quanto boa parte da população (BOWLES; GORDON; WEISSKOPF, 1984, p. 77-79; 1990, p. 57-61; LIPPIT, 2010, p. 50-51). 
Gráfico 2 - Produtividade e salário real médio do setor privado, EUA (1947-2016)

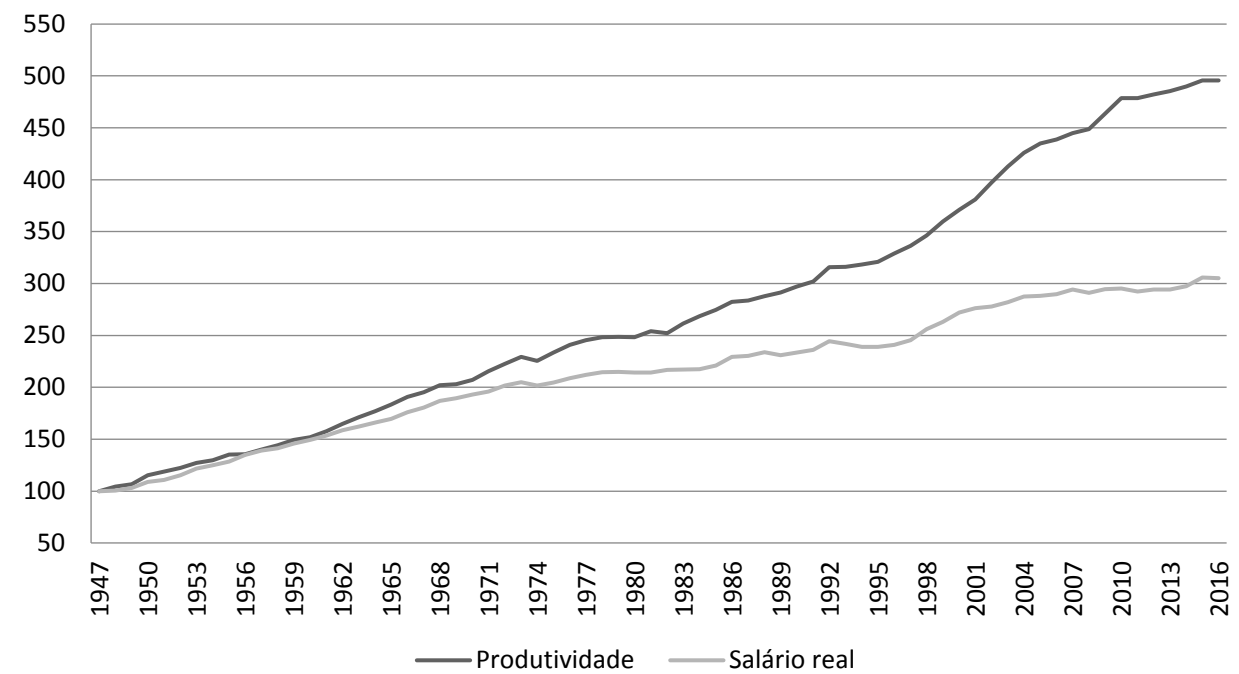

Fonte: baseado nos dados apresentados por Bureau of Labor Statistics. ${ }^{11}$

As instituições análogas ao “acordo capitalistas-cidadãos” são, para McDonough (1994, p. 115-122), o "Estado keynesiano conservador" e a "coalizão democrata". Segundo o autor, essas instituições foram sendo criadas a partir do governo Roosevelt, quando foram desenvolvidas políticas de intervenção que não ameaçavam o poder corporativo. Tais políticas marcaram uma inflexão do Partido Democrata e a consolidação do partido como o principal do país, atraindo setores que iam desde frações da classe média, passando pelos trabalhadores sindicalizados, até minorias como os judeus e os negros. Ademais, segundo o autor, a colaboração entre Estado e empresas na mobilização para a Segunda Guerra Mundial e, posteriormente, para a Guerra da Coreia contribuiu para que a resistência ao intervencionismo, por parte de setores mais conservadores da sociedade, fosse quebrada.

A quarta instituição destacada pela abordagem (BOWLES; GORDON; WEISSKOPF, 1990, p. 61-63; LIPPIT, 2010, p. 51) é a chamada "contenção da rivalidade intercapitalista", que seria resultante dos mercados oligopolizados por grandes firmas, fenômeno que teria se iniciado já na virada do século XIX para o século XX e que teria se intensificado após a Grande Depressão e, especialmente, com o domínio econômico dos Estados Unidos, decorrente da desestruturação das economias capitalistas da Europa e da Ásia, em virtude da destruição causada pela Segunda Guerra Mundial.

A última estrutura destacada pela abordagem é o "sistema financeiro", sublinhado por Victor Lippit (2010, p. 51-52), tomando como referência a contribuição 
de Martin Wolfson (1994). Segundo ambos os autores, a reforma do setor financeiro americano em resposta à Grande Depressão contribuiu com a promoção da estabilidade econômica ao mesmo tempo em que estimulou a lucratividade. A separação entre bancos comerciais e de investimento, a introdução dos seguros de depósito e a ampliação da supervisão foram algumas das reformas introduzidas na década de 1930.

Depois de cerca de vinte anos de resultados econômicos relativamente bons, o próprio funcionamento das principais instituições características do período esteve associado à grave crise do começo dos anos 1970. No plano internacional, o arcabouço institucional não foi capaz, a partir de meados de 1960, de acompanhar a evolução econômica mundial. Isso acarretou uma consequente perda de competitividade e a erosão das mesmas instituições que promoveram o elevado crescimento anterior. Do ponto de vista interno, outras razões para a crise seriam o conflito distributivo, a diminuição dos ganhos de produtividade e a lucratividade declinante dos grandes setores econômicos do país, como os setores petrolífero, nuclear, de mineração, químico, etc.

Já na década de 1960, os Estados Unidos começaram a perder competitividade para outras grandes potências, como Europa e Japão. O desenvolvimento das indústrias dessas regiões contribuiu para que os Estados Unidos fossem, paulatinamente, diminuindo seus superávits comerciais. A economia mundial foi, no pós-guerra, se abrindo mais e mais ao comércio internacional. No caso dos EUA, por exemplo, o volume das importações em relação ao PIB passou de cerca de $4 \%$ no final da década de 1940 para quase $12 \%$ trinta anos depois (BOWLES; GORDON; WEISSKOPF, 1990, p. 75-77).

Além de as empresas dos Estados Unidos perderem competitividade para as empresas europeias e japonesas, a derrota na guerra do Vietnã e as duas crises do petróleo foram fatores que contribuíram para o declínio do poder internacional. Autores da Eesa argumentam que a falta de capacidade de reestruturação da economia americana foi provocada, em parte, pelos intensivos gastos militares (BOWLES; GORDON; WEISSKOPF, 1984, p. 81-82; 1990, p. 63-66).

Outro fator que teria contribuído com a perda de competitividade, com a diminuição dos ganhos de produtividade e com a pressão inflacionária teria sido o aumento no número de regulamentações para proteger os consumidores e trabalhadores, que se enquadram no "acordo capitalistas-cidadãos". Entre as regulamentações, destacam-se: National Highway Traffic Safety Comission, Environmental Protection Administation e Occupational Safety and Health Administration, criadas em 1970, além da Mine Enforcemente and Safety Administration e da Consumer Production Safety Administration, criadas em 1973 (BOWLES; GORDON; WEISSKOPF, 1984, p. 91-97; 1990, p. 72-75). 
Do ponto de vista macroeconômico, a perda de competitividade e a pressão inflacionária não foram solucionadas por meio de uma recessão, já que o aumento de gastos públicos em razão da Guerra do Vietnã e da Guerra Contra a Pobreza mantinha a economia superaquecida (BOWLES; GORDON; WEISSKOPF, 1990, p. 81-85).

No período de apogeu da estrutura social de acumulação do pós-guerra, entre os anos de 1950 e 1965, o Índice de Preço do Consumidor anual girou em torno de dois pontos percentuais. Quanto à taxa de desemprego, estabilizou-se abaixo de 6\% até o início da década de 1970. O aumento do poder de barganha dos trabalhadores e o momento econômico favorável aos Estados Unidos fizeram índices como inflação e nível de desemprego ficarem relativamente baixos até o início da década de 1970, conforme pode ser observado no Gráfico 3, a seguir.

É possível verificar a relação inversa e estável entre desemprego e inflação entre meados da década de 1950 e início dos anos 1970, que ficou conhecida como Curva de Phillips. Já após os anos 1970, fatores como a crise do petróleo e o acirramento do conflito distributivo refletiram na inflação, que atingiu picos de mais de $11 \%$ ao ano em 1974 e 1979 e 13,5\% em 1980. Ao contrário do que previa a Curva de Phillips, o aumento do desemprego, que ficou em média em 7,5\% ao ano entre 1975 e 1982, não reduziu rapidamente a taxa de inflação. Esse fenômeno, que ficou conhecido como estagflação, marcou a erosão da estrutura social de acumulação do pós-guerra.

Gráfico 3 - Relação entre a taxa de inflação e a taxa de desemprego (1956-1982)

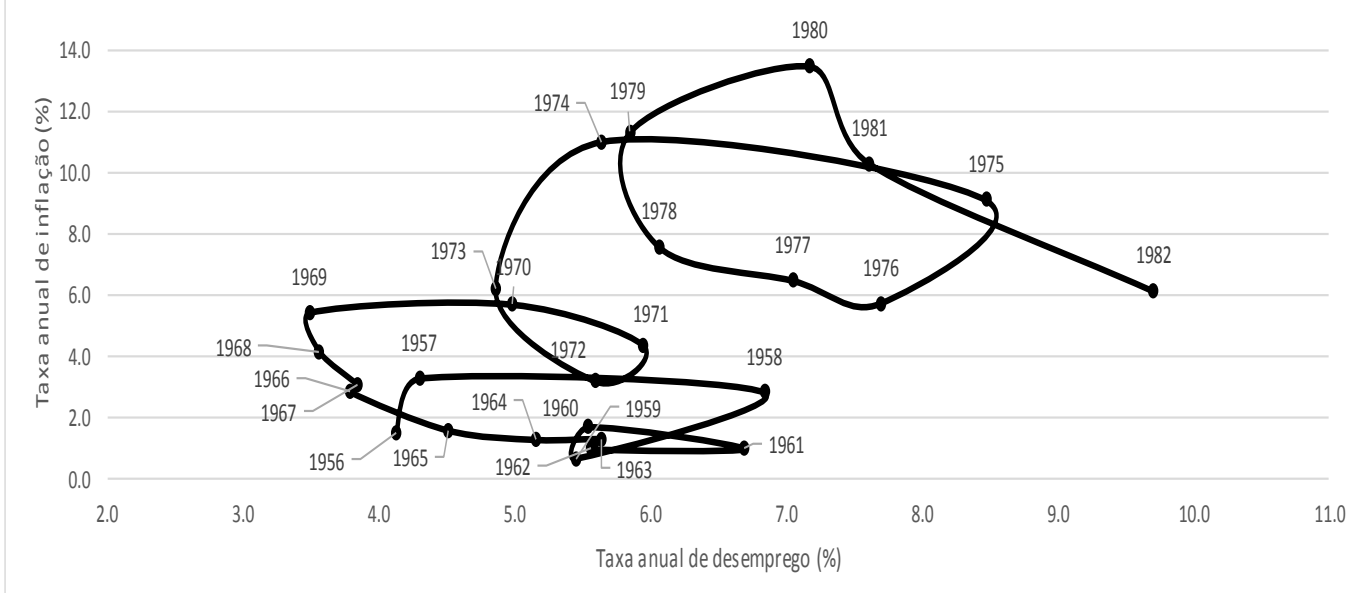

Fonte: baseado nos dados apresentados por Bureau of Labor Statistics. ${ }^{12}$ 
A estagflação, um dos principais problemas econômicos da década de 1970, seria, segundo os autores da Eesa, desenvolvida pelos conflitos de distribuição de renda e de riqueza entre a classe trabalhadora e os empresários, além de um excesso de investimento por parte do governo na área militar, que superaqueceu a economia e impediu a reversão dos problemas econômicos que começaram vir à tona.

Como possível alternativa para a recuperação do período, a teoria da Eesa sugeria, na década de 1980, uma diminuição de gastos em várias áreas, como os setores de energia, militar, de saúde e de propaganda. Além disso, foram propostos o aumento do emprego produtivo e a redução de cargos de supervisão. A aplicação dessas ações poderia levar, segundo os autores, a uma elevação de cerca de 50\% na produção útil das corporações (BOWLES; GORDON; WEISSKOPF, 1984, p. 160-178).

\section{Estrutura social de acumulação neoliberal e a crise do subprime}

A partir da crise de 1970, o comportamento macroeconômico do país foi caracterizado pelo crescimento bem mais lento em comparação com as décadas de 1940, 1950 e 1960 (conforme a Tabela 1, apresentada na seção anterior). As décadas de 1980 e 1990 foram períodos nos quais os autores da Eesa consideravam que não havia uma estrutura social de acumulação estabelecida nos Estados Unidos (BOWLES; GORDON; WEISSKOPF, 1990; GORDON, 1994; KOTZ; MCDONOUGH; REICH, 1994b; KOTZ, 2001). O crescimento relativamente baixo pelo qual a economia do país passava indicava a continuação da crise econômica de 1970 e não a presença de uma estrutura social de acumulação consolidada, que possibilitaria crescimento rápido e estável:

Muitos seguidores da abordagem da estrutura social de acumulação veem a condição atual do capitalismo mundial como uma continuação da estagnação que começou no final dos anos 1960 ou começo dos anos 1970. A longa duração desse período de estagnação resulta da falha, até agora, em criar uma estrutura social de acumulação nova e viável. Um novo período de expansão vigorosa requereria um novo conjunto de instituições internacionais efetivas, assim como instituições nacionais efetivas, nos principais países capitalistas (KOTZ; MCDONOUGH; REICH, 1994b, p. 307-308, tradução nossa). ${ }^{13}$

A partir de 2006, alguns autores da Eesa reconsideraram a afirmação de que o comportamento do capitalismo contemporâneo está associado à ausência de uma estrutura social de acumulação. Wolfson e Kotz (2010), por exemplo, reinterpretaram o conceito de estrutura social de acumulação, que passou a ser entendido 
como um conjunto de instituições voltadas mais para estabilizar os conflitos sociais e garantir a acumulação de capital do que para promover o rápido crescimento. $\mathrm{O}$ conceito foi reinterpretado para conseguir compreender o funcionamento do capitalismo com menores taxas de crescimento e maior instabilidade econômica.

Desse modo, estudos recentes da Eesa que analisam o capitalismo contemporâneo concluem que as instituições desse período pertencem a uma nova etapa do capitalismo, chamada de estrutura social de acumulação neoliberal. O arcabouço institucional neoliberal é composto por um conjunto de instituições que prevaleceram a partir de 1980. Entre as principais características desse sistema, Kotz enumera:

1) desregulamentação de negócios e finanças, tanto a nível nacional como internacional, para permitir ao chamado "livre mercado" dominar e alcançar a livre mobilidade do capital; 2) privatização de muitos serviços do Estado; 3) renúncia à política fiscal discricionária que visava à moderação do ciclo econômico e à manutenção do desemprego relativamente baixo; 4) reduções acentuadas nas despesas sociais do Estado; 5) redução de impostos sobre empresas e indivíduos ricos; 6) grande ataque dos grandes capitalistas e do Estado sobre os sindicatos; 7) mudança no processo de trabalho, diminuindo a dependência de empregados de longo prazo e aumentando o uso de trabalhadores temporários e de meio período; 8) competição desenfreada e fraudulenta que substituiu o "comportamento corresponsável" que grandes corporações haviam praticado no capitalismo regulado do pós-Segunda Guerra; e 9) introdução de princípios de mercado dentro das grandes corporações, incluindo a mudança de escolha do CEO entre os empregados com carreira na empresa, passando a contratar de fora, em um mercado de CEOs (2009, p. 307, tradução nossa). ${ }^{14}$

O capitalismo neoliberal começou a ser construído nos Estados Unidos e no Reino Unido, mas logo depois suas práticas começaram a se espalhar pelo mundo. Em especial nos EUA, o neoliberalismo foi identificado como um sistema econômico com característica menos regulamentada. De acordo com Kotz (2009), as nove principais instituições do arcabouço neoliberal promoveram o desenvolvimento econômico, mas com condições que colaboraram para o surgimento da crise de 2008 , considerada pelo autor uma "crise sistêmica". ${ }^{15}$

Kotz entende que cada uma das principais instituições da época contribuiu para o aumento da desigualdade social, o fortalecimento da classe capitalista e o enfraquecimento da classe trabalhadora, além do alto endividamento financeiro que caracterizou a última crise. Segundo Wolfson e Kotz:

Nos EUA, o neoliberalismo tem significado crescente desigualdade de renda, desregulamentação dos mercados industrial e financeiro, influência crescente dos mercados financeiros na tomada de decisões corporativas, política fiscal que enfatiza cortes de impostos para os ricos e cortes em programas sociais, política monetária que coloca uma ênfase maior em redução da inflação do que em desemprego e crescimento econômico lento (WOLFSON; KOTZ, 2010, p. 72, tradução nossa). ${ }^{16}$

Teoria e Evidência Econômica - a. 24, n. 50, p. 26-50, jan./jun. 2018 
No que se refere à desigualdade entre capitalistas e trabalhadores, Kotz (2009) argumenta que alguns dos principais fatores que prejudicaram a classe trabalhadora foram a desregulamentação de diversos setores, o ataque contra os sindicatos, a ampliação da concorrência internacional. Todos esses fatores teriam contribuído com a deterioração do poder de barganha que os trabalhadores adquiriram no pós-Segunda Guerra e, assim, propiciaram diminuição dos aumentos salariais (e mesmo redução do salário real em vários setores).

Durante a fase do pós-guerra, a distribuição de renda entre as famílias era relativamente favorável à classe trabalhadora. Já no capitalismo neoliberal, a concentração de renda voltou a aumentar e atingiu níveis similares aos da década de 1930. O Gráfico 4 ilustra que, na década de 1920, 1\% da população detinha até $20 \%$ da renda total. A partir da década de 1930, a parcela da renda apropriada pelo percentil mais elevado declinou até atingir cerca de $10 \%$ em 1980. A partir desse período, essa porcentagem foi aumentando gradativamente, até chegar novamente a mais de $20 \%$ da renda total, no ano de $2012 .{ }^{17}$

Outro indicador do aumento da desigualdade é o crescimento da produtividade superior ao crescimento dos salários, que pode ser observado no Gráfico 2, apresentado na seção anterior, que mostra o nível da produtividade crescente, a partir de 1980, totalmente descolado do nível salarial, que cresceu muito menos durante todo o período. É possível visualizar que, entre 1968 e 2003, o nível de produtividade aumentou em pouco mais de $100 \%$, enquanto o nível salarial evoluiu cerca de $50 \%$.

Grafico 4 - Participação do percentil mais rico na renda dos EUA (1913-2014)

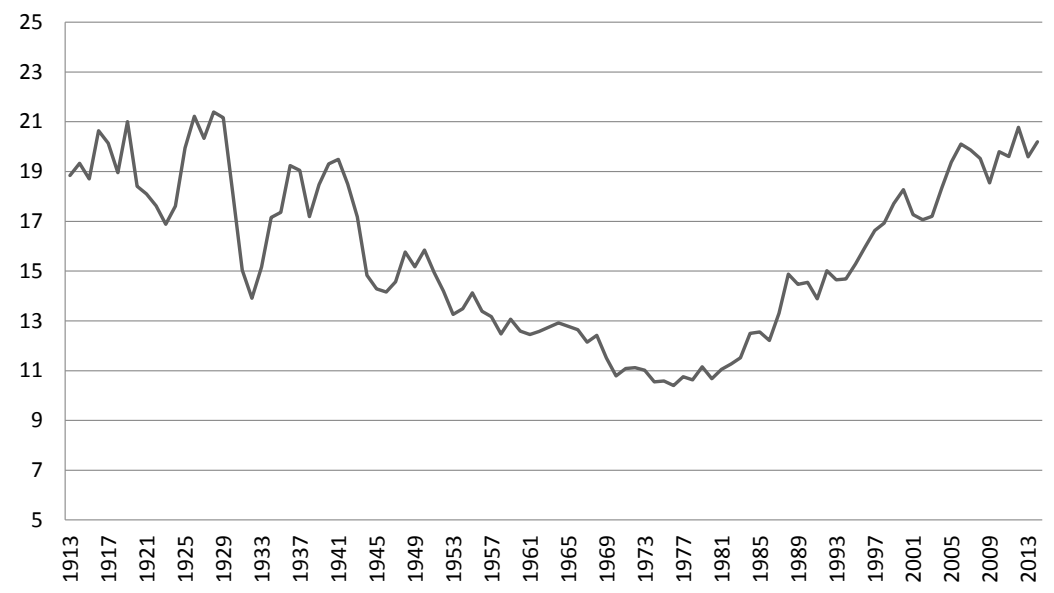

Fonte: baseado nos dados apresentados por The World Wealth and Income Database. ${ }^{18}$ 
O baixo crescimento do salário real médio poderia ter provocado uma crise de superprodução. Entretanto, tal fenômeno não ocorreu, pois as empresas garantiram uma forma de obter maior lucro, com base no endividamento das famílias e na especulação financeira. $\mathrm{O}$ endividamento das famílias estadunidenses foi uma estratégia promovida pela própria estrutura social de acumulação neoliberal, para garantir a ampliação tanto do consumismo quanto da demanda agregada. Um exemplo do endividamento da população foi a bolha imobiliária dos anos 2000 . Grande número de pessoas conseguiu adquirir suas moradias mesmo não tendo renda nem ativos disponíveis para pagá-las.

Kotz (2009) argumenta que o neoliberalismo acirrou graves contradições. A expansão econômica do início do século foi causada principalmente graças ao endividamento imobiliário promovido pelas empresas financeiras. Essa estratégia só foi possível dentro da estrutura social de acumulação neoliberal, que associa produtividade crescente a salários estagnados, em virtude da concorrência internacional e da perda da capacidade de barganha da classe trabalhadora. Graças a esse sistema, a dívida familiar cresceu consideravelmente (KOTZ, 2009 p. 10), como ilustrado no Gráfico 5, a seguir.

O nível de endividamento já se encontrava bastante elevado em meados da década de 1990, tendo em vista que era de cerca de $95 \%$ da renda líquida disponível entre os anos de 1995 e 1996. Em virtude do boom do setor imobiliário, o endividamento das famílias superou $140 \%$ da renda líquida disponível nos anos de 2006 e 2007. Cabe ressaltar que, além da dívida imobiliária, as dívidas estudantis e de cartão de crédito eram as outras duas fontes principais do endividamento das famílias americanas.

Gráfico 5 - Proporção entre dívida das famílias e renda líquida disponível (1995-2016)

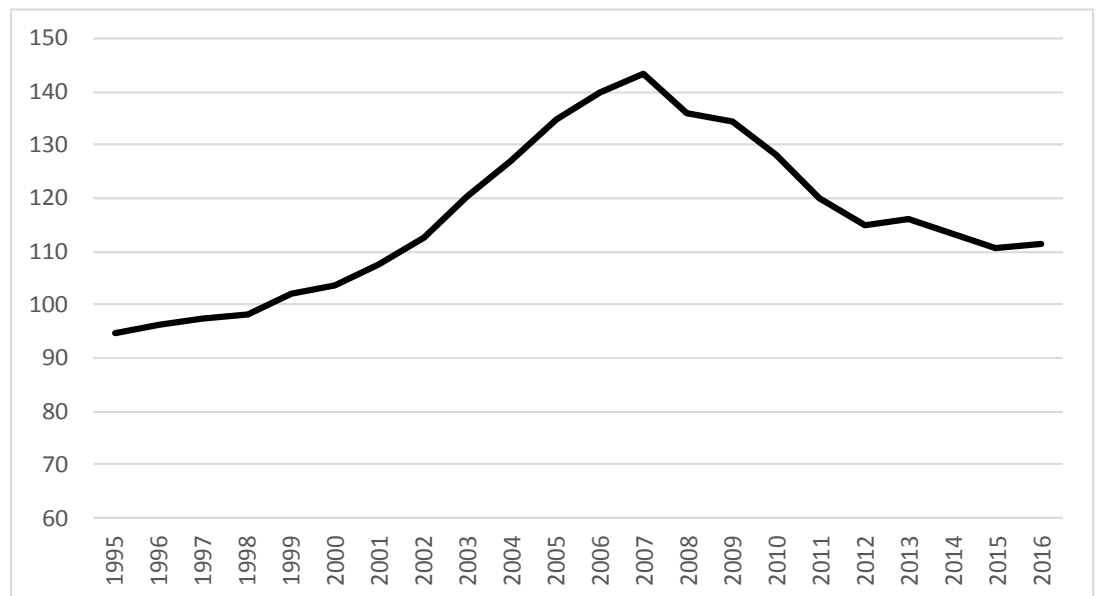

Fonte: baseado nos dados apresentados pela Organização para a Cooperação e Desenvolvimento Econômico. ${ }^{19}$ 
O ano de 2007 foi marcado pela eclosão da crise do subprime. No ano anterior, os preços dos imóveis já tinham começado a despencar, e, em 2007, a bolha imobiliária finalmente explodiu, resultado de um setor desregulamentado, no qual mesmo as pessoas que não tinham renda disponível comprovada podiam refinanciar sua dívida a taxas de juros baixas, em virtude da securitização das dívidas. Porém, a crise de 2008-2009 levou a população a não ter condições de arcar com as dívidas acumuladas. Um dos indicadores da deterioração da atividade econômica foi a taxa de desemprego no país, que ficou entre 8\% e 10\% de 2009 a 2013 (LIPPIT, 2014).

Como consequência, a crise se estendeu a todo sistema financeiro do país. Muitos bancos comerciais declararam falência ou sofreram intervenção do governo. Um exemplo importante e ilustrativo da magnitude da crise financeira nos Estados Unidos foi a falência do banco Lehman Brothers, uma das principais empresas do setor financeiro do país (LIPPIT, 2014).

Do ponto de vista da Eesa, a crise do subprime marcaria a dissolução da estrutura social de acumulação (KOTZ; MCDONOUGH, 2010; LIPPIT, 2010, 2014). Como foram as próprias instituições predominantes na economia estadunidense entre a década de 1980 e o ano de 2007 que geraram o ambiente propício para gênese de uma crise de tamanha gravidade, as próprias instituições terão que ser alteradas para dar origem a um novo período de crescimento e de estabilidade:

A crise atual, que, no momento deste escrito (maio de 2009), já é a mais severa desde a Grande Depressão, claramente marca o colapso da estrutura social de acumulação neoliberal. É uma crise sistêmica genuína, em que não vai ser possível remontar o antigo sistema, a antiga estrutura social de acumulação, com reformas modestas no sistema financeiro e em outras áreas, que colapsaram graças às contradições das instituições características. Mais uma vez o capitalismo dos EUA vai ser forçado a se reinventar (LIPPIT, 2010, p. 69, tradução nossa). ${ }^{20}$

As discussões acerca das possibilidades do futuro do capitalismo nos Estados Unidos (e no mundo como um tudo) estão alimentando uma nova geração de pesquisas da escola da estrutura social de acumulação, que são tratadas na próxima seção.

\section{Desafios teóricos e perspectivas para o futuro do capitalismo}

Ao longo do tempo, a Eesa passou por algumas inflexões. Nos primeiros trabalhos (GORDON, 1978, 1980), a abordagem foi desenvolvida para realizar a mediação entre Marx e os ciclos de Kondratiev. Nas duas décadas seguintes, os principais

Teoria e Evidência Econômica - a. 24, n. 50, p. 26-50, jan./jun. 2018 
autores da escola refinaram sua análise e aprofundaram a compreensão do capitalismo americano do pós-guerra (GORDON; EDWARDS; REICH, 1982; BOWLES; GORDON; WEISSKOPF, 1984, 1990; KOTZ; MCDONOUGH; REICH, 1994a); entretanto, a abordagem demorou para reconhecer que o arcabouço institucional que prevaleceu após a década de 1980 promovia acumulação de capital de uma forma diferente, mais devagar e menos estável. Foi somente a partir de publicações realizadas em 2006 que a Eesa reconheceu o neoliberalismo como um tipo de capitalismo viável (KOTZ, 2006; LIPPIT, 2010; WOLFSON; KOTZ, 2010).

Críticos da abordagem argumentam que a dificuldade em compreender o neoliberalismo como uma etapa do capitalismo decorreu da ausência de uma análise mais aprofundada do modo de produção capitalista e da adoção, por décadas, da hipótese injustificada de que o funcionamento normal do capitalismo pressupõe crescimento elevado e estável (MAVROUDEAS, 2006; COUTROT, 2009; MELLO FILHO, 2016). ${ }^{21}$ Os mesmos críticos apontam que a retomada de autores clássicos da economia heterodoxa, notadamente Marx e Keynes, pode ser de suma importância para o refinamento dos conceitos da escola.

Mais recentemente, um novo equívoco ocorreu. Os principais desenvolvedores da abordagem (KOTZ; MCDONOUGH, 2010; LIPPIT, 2010, 2014) subestimaram a resiliência do neoliberalismo ao argumentar que a crise do subprime marcaria o fim da estrutura social de acumulação neoliberal. Com o intuito de evitar que os problemas teóricos e de análise de conjuntura continuem ocorrendo com tanta frequência na escola, é importante que os autores articulem mais adequadamente a compreensão das características gerais do modo de produção capitalista com suas características históricas específicas. Além disso, é essencial que os autores não subestimem nem a esfera política, nem o poder das diferentes frações da classe capitalista. Felizmente, em um texto recente, David Kotz (2017) reavalia sua posição de que o neoliberalismo está condenado e elabora uma análise mais interessante da conjuntura política dos Estados Unidos e do mundo como um todo.

Em se tratando dos possíveis caminhos que o capitalismo pode seguir, o que determina mudanças institucionais são a própria luta de classes e o aprendizado sobre as falhas que causaram a crise. Kotz (2017) diz que a crise, ocorrida entre 2008 e 2009 nos EUA, que afetou o mundo todo, pode resultar em três possíveis novos tipos de capitalismo capazes de reestruturar a economia. São eles: “(1) um regime nacionalista de direita com características estatais repressivas e uma postura agressiva no sistema global; (2) um capitalismo reformado baseado no compromisso capital-trabalho; (3) uma transição para o socialismo" (KOTZ, 2017, p. 4, tradução nossa). ${ }^{22}$

Teoria e Evidência Econômica - a. 24, n. 50, p. 26-50, jan./jun. 2018 
Em relação à possibilidade de uma reestruturação da vida econômica comandada por forças políticas de esquerda, Kotz cita alguns movimentos que mostram uma força relativa da esquerda no cenário político internacional:

As manifestações do Occupy Wall Street em 2010, as revoltas da Primavera Árabe em 2011, as vitórias do movimento eleitoral radical socialista Syriza na Grécia, em 2015, a liderança do Partido Trabalhista britânico pelo "socialista não reconstruído" Jeremy Corbin em 2015 e os 12 milhões de votos para o autodenominado senador socialista Bernie Sanders nas eleições primárias presidenciais dos EUA em 2016 (2017, p. 4, tradução nossa). ${ }^{23}$

Em contrapartida, a presença de líderes nacionalistas no poder demonstra outra possível direção para o capitalismo. Nesse sentido, Kotz aborda que "os nacionalistas de direita subiram ao poder na Polônia, Hungria, Turquia, Índia e Filipinas, e até mesmo nos Estados Unidos" (2017, p. 4, tradução nossa). ${ }^{24}$ Kotz (2017) argumenta que os movimentos de esquerda não apresentaram força suficiente para alterar as características prevalecentes do capitalismo atual. Um exemplo foi o governo da Grécia que, em 2015, não foi capaz de romper com o sistema econômico neoliberal. Essa realidade pode mostrar que a condição econômica mundial tende a promover uma guinada à direita no sistema econômico. Essa possível nova etapa do capitalismo também promove alguns riscos de dimensão mundial, por exemplo, as tensões entre as potências nucleares, como Estados Unidos, Rússia e China (KOTZ, 2017).

Quanto ao governo Donald Trump, ainda não seria possível fazer uma análise concreta. Segundo Kotz (2017), a administração de Trump é muito dividida entre neoliberais, corporativistas, privatizadores e outros segmentos que podem dificultar a efetivação das promessas mais radicais do presidente. Mesmo assim, algumas propostas desse governo, já citadas pelo próprio presidente - a diminuição de impostos para os mais ricos, o protecionismo e a ampliação da privatização -, segundo Kotz (2017, p. 6), poderiam provocar o retorno da estagnação econômica.

Mesmo que o cenário econômico mundial em geral seja de baixo crescimento, pelo menos nos Estados Unidos foi possível recuperar o capital destruído durante a crise em 2009. Nesse sentido, a discussão sobre o provável fim do capitalismo neoliberal abordada pela Eesa ainda não foi encerrada, pelo fato de a última crise não derrubar o arcabouço institucional prevalecente. O futuro do modo de produção capitalista, ou mesmo a superação dele, depende exclusivamente das condições políticas e sociais e não pode ser determinado de antemão pela teoria econômica.

Além de possíveis novos cenários para o capitalismo dos Estados Unidos e do mundo como um todo, a Eesa tem se debruçado sobre outros temas de grande relevância, que podem dar origem a novas safras interessantes de trabalhos nos 
próximos anos. Alguns dos assuntos que estão sendo investigados no momento e ainda não foram publicados são a introdução do meio ambiente no arcabouço teórico da abordagem e a estrutura social de acumulação chinesa (YAN; KOTZ; MCDONOUGH, 2017).

\section{Comentários finais}

A abordagem em termos de estruturas sociais de acumulação surgiu no final da década de 1970, tendo como objetivo compreender a conjuntura econômica e as mudanças históricas da economia americana ao longo do século XX. Para cumprir tais objetivos, a escola desenvolveu um tipo de análise que procura conjugar o marxismo com o keynesianismo, o institucionalismo e a história econômica. Além disso, a abordagem considera que a economia não pode ser entendida sem que se leve em conta as demais ciências humanas, como a sociologia, a política, o direito, a história e outras áreas. Tais características fazem com que a Eesa desenvolva obras relevantes, que deveriam ser melhor estudadas e compreendidas pelo ambiente acadêmico brasileiro. Algumas das contribuições relevantes da abordagem foram as investigações da estrutura social de acumulação do pós-guerra, do neoliberalismo e da crise do subprime.

Do ponto de vista teórico, a definição de uma estrutura social de acumulação mudou ao longo do tempo. Nos trabalhos das décadas de 1980 e 1990, uma estrutura social de acumulação era entendida como um conjunto de instituições que possibilita a acumulação rápida de capital por um longo período de tempo. A partir do ano 2006, devido à persistência do neoliberalismo, o conceito de estrutura social de acumulação foi reinterpretado como um conjunto de instituições que estabiliza os conflitos sociais e possibilita a acumulação de capital. De modo geral, a escola considera que as principais instituições, relevantes para o entendimento do tipo de capitalismo predominante, são construídas no plano nacional, mas este é mais um aspecto que está sendo rediscutido nos trabalhos de última geração.

Recentemente, as graves crises econômicas e ecológicas que atingem diversos países ao redor do mundo têm estimulado novas ondas de pesquisa da escola, que ainda não possui um arcabouço teórico totalmente consolidado. Pelo contrário, a Eesa é uma abordagem em desenvolvimento, como a própria releitura do conceito central da escola ao longo do tempo deixa claro. O retorno aos autores clássicos da economia heterodoxa, principalmente Marx e Keynes, pode ser fundamental para que a abordagem consolide de maneira mais consistente sua interpretação do capitalismo. 


\title{
The social structures of accumulation analysis of United States economy between the post-war and the beginning of the 21 st century
}

\begin{abstract}
The main objective of this work is to present the contribution of the social structures of accumulation school to the understanding of the transformations of American capitalism that took place between the post-war period and the beginning of the 21st century. According to the approach, the post-war social structure of accumulation, built in the geopolitical context of the Cold War, was characterized by agreements between the workers and the capitalists and between the latter and the citizens. Such institutional arrangements enabled high economic growth and significant real wage gains. The approach presented some problems to analyse the type of capitalism prevailing in the United States after the stagflation of the 1970s and had to change the meaning of its main concept to analyze neoliberal capitalism.
\end{abstract}

Keywords: School of social structures of accumulation. Economic history of the United States. Neoliberalism.

\section{El análisis de la escuela de las estructuras sociales de acumulación sobre la economía de los Estados Unidos entre el post-guerra y el inicio del siglo XXI}

\section{Resumen}

El objetivo principal del trabajo es presentar la explicación de la escuela de las estructuras sociales de acumulación para las transformaciones del capitalismo estadounidense ocurridas entre la posguerra y el inicio del siglo XXI. De acuerdo con el enfoque, la estructura social de acumulación de la posguerra, construida en el contexto geopolítico de la Guerra Fría, fue caracterizada por acuerdos entre los trabajadores y los capitalistas y entre éstos y los ciudadanos. Estos arreglos institucionales posibilitaron tasas de crecimiento elevadas y significativas ganancias de salario real. El enfoque tuvo alguna dificultad en comprender el tipo de capitalismo predominante en los Estados Unidos después de la estaflación de la década de 1970 y tuvo que alterar el significado de su concepto principal para analizar el capitalismo neoliberal.

Palabras clave: Escuela de las estructuras sociales de acumulación. Historia económica de los Estados Unidos. Neoliberalismo. 


\section{Notas}

1 O presente artigo foi baseado no trabalho de conclusão de curso de Amanda Mayara da Silva Bento, que se beneficiou dos comentários de Múcio Tosta Gonçalves. Este não possui responsabilidade pelos equívocos remanescentes.

2 A economia política radical critica a abordagem neoclássica, considerada muito abstrata, a-histórica e incapaz de lidar com os problemas da sociedade americana da época.

3 Não é objetivo do presente artigo desenvolver uma análise comparativa entre a Eesa, a escola francesa da regulação, a abordagem neoschumpeteriana e escolas semelhantes. Tal comparação já foi realizada por alguns autores (JESSOP; SUM, 2006; MAVROUDEAS, 2006; CHAVANCE, 2009; O'HARA, 1994; (MELLO FILHO, 2016).

4 A metodologia de pesquisa que serviu de base para a elaboração deste artigo consistiu, em primeiro lugar, na revisão crítica da literatura elaborada pela Eesa sobre a economia dos Estados Unidos entre o pós-guerra e o início do século XXI; em segundo lugar, para ilustrar os argumentos principais da escola, na apresentação dos dados estatísticos trabalhados pelos autores da Eesa. As duas principais obras da Eesa que tratam sobre a economia estadunidense no pós-guerra são Beyond the waste land (1984) e After the waste land (1990), de Samuel Bowles, David M. Gordon e Thomas E. Weisskopf. Além delas, serão analisados capítulos que tratam da história econômica dos Estados Unidos, publicados em duas obras fundamentais para a consolidação da escola, os livros Social structures of accumulation: the political economy of growth and crisis (KOTZ; MCDONOUGH; REICH, 1994a) e Contemporary capitalism and its crises: social structure of accumulation theory for the 21st Century (MCDONOUGH; REICH; KOTZ, 2010). Estes dois livros procuram apresentar o estado da arte da escola, respectivamente, no início da década de 1990 e no início do século XXI.

5 "We propose that an intermediate level of analysis, focusing on the logic of long swings and stages of capitalism, is necessary for an understanding of capitalist development. This intermediate anlysis is intended to complement both the traditional and abstract Marxian approach to capitalist development and the more recent concrete analyses of everyday life" (GORDON; EDWARDS; REICH, 1982, p. 22).

6 Um dos principais desenvolvedores da abordagem em termos de estruturas sociais de acumulação nas últimas décadas, Terrence McDonough (1994, p. 114-126) destaca instituições similares às descritas por Bowles, Gordon e Weisskopf $(1984,1990)$ para compreender o capitalismo estadunidense do pós-guerra: "Estado keynesiano conservador", "relações capital-trabalho", "coalizão democrata", "dominância internacional estadunidense e ideologia da Guerra Fria".

7 As instituições e as estruturas sociais de acumulação são normalmente descritas pela abordagem como construções de âmbito nacional. Entretanto, nos últimos anos, algumas obras importantes têm adotado o ponto de vista de que as instituições e as estruturas sociais de acumulação podem ser transnacionais (KOTZ, MCDONOUGH, 2010). Por fugir ao escopo do presente trabalho, esse debate não é explorado nesta discussão.

8 Disponível em: <https://www.bea.gov/data/gdp/gross-domestic-product>. Acesso em: 12 set. 2017.

9 "Many analysts have simplified the character of this new system of corporate power, emphasizing one or another single dimension of transformation. Some emphasize the much greater role of the government, calling it the 'welfare state' or the 'mixed economy'. Others have focused on its international dimensions, concentrating on the American Century or its 'neo-imperialist' relations. Others have pointed to the rise of industrial unions as its central distinguishing feature" (BOWLES; GORDON; WEISSKOPF, 1984, p. $63 ; 1990$, p. 48).

10 Disponível em: <https://www.bls.gov/news.release/wkstp.t01.htm>. Acesso em: 31 out. 2017.

11 Disponível em: <www.bls.gov/news.release/prod2.nr0.htm>. Acesso em: 31 out. 2017.

12 Dados para a inflação disponíveis em: <https://www.bls.gov/cpi/tables/supplemental-files/historical-cpi-u-201808.pdf>. Acesso em: 10 set. 2017. Dados para o desemprego disponíveis em: <https://data.bls.gov/ timeseries/LNU04000000?periods=Annual+Data\&periods_option=specific_periods\&years_option=all_ years>. Acesso em: 10 set. 2017.

13 "Most followers of the social structure of accumulation approach view the current condition of world capitalism as a continuation of the stagnation that began in the late 1960s or early 1970s. The long duration of this period of stagnation results from the failure so far to create a new, viable social structure of accumulation. A new period of vigorous expansion would require a new set of effective international institutions, as well as effective domestic institutions in the major capitalist countries" (KOTZ; MCDONOUGH; REICH, 1994b, p. 307-308).

Teoria e Evidência Econômica - a. 24, n. 50, p. 26-50, jan./jun. 2018 
14 “1) deregulation of business and finance, both domestically and internationally, to allow the so-called "free market" to rule and to achieve free mobility of capital; 2) privatization of many state services; 3) the renunciation of discretionary fiscal policy which had been aimed at moderating the business cycle and keeping unemployment relatively low; 4) sharp reductions in state social spending; 5) reduction of taxes on business and wealthy individuals; 6) an attack by big business and the state on trade unions; 7) a shift in the labor process from reliance on long-term employees to increasing use of temporary and part-time workers; 8) unrestrained, cutthroat competition which replaced the "co-respective behavior" that large corporations had practiced in postwar regulated capitalism; and 9) the introduction of market principles inside large corporations, including a shift from choosing the CEO from among career employees of the firm to hiring from the outside in a market for CEOs" (KOTZ, 2009 p. 307).

15 No contexto da teoria da Eesa, quando a economia passa por uma crise severa, na qual a estrutura institucional prevalecente não possibilita a retomada da estabilidade econômica, essa crise é considerada "sistêmica" e só desaparece com o surgimento de um novo arcabouço institucional.

16 "In the U.S., neoliberalism has meant increased income inequality, deregulation of industrial and financial markets, increased influence of financial markets over corporate decision-making, fiscal policy emphasizing tax cuts for the wealthy and cutbacks in social programs, monetary policy that puts a greater emphasis on reducing inflation than unemployment, and relatively sluggish economic growth" (WOLFSON; KOTZ, 2010, p. 72).

17 Kotz (2009) faz referência aos dados de concentração de renda elaborados pelo The World Wealth and Income Database, instituto liderado, entre outros, por Piketty e Saez.

18 Disponível em: <https://wid.world/data/>. Acesso em: 15 out. 2017.

19 Disponível em: <https://data.oecd.org/hha/household-debt.htm>. Acesso em: 15 out. 2017.

20 "The current downturn, which at the time of this writing (May 2009) is already the most severe since the Great Depression overall, clearly marks the collapse of the neoliberal SSA. It is a genuine systemic crisis in that it will not be possible to put together the old system, the old SSA, with modest reforms in the financial system and other areas where the contradictions in the institutions that characterized it have brought about its collapse. Once again, U.S. Capitalism will be forced to reinvent itself" (LIPPIT, 2010, p. 69).

21 Mello Filho (2016) discute com mais detalhes a história da Eesa e aprofunda as críticas apresentadas neste estudo.

22 "(1) a right-wing nationalist regime with statist and repressive features and an aggressive posture in the global system, (2) are formed capitalism based on capital-labor compromise, (3) a transition to socialism” (KOTZ, 2017 p. 4).

23 “Occupy Wall Street demonstrations in 2010, the Arab Spring uprisings in 2011, the electoral victory of the radical socialist movement Syriza in Greece in 2015, the takeover of the British Labor Party by 'unreconstructed socialist' Jeremy Corbin in 2015, and the 12 million votes for self described socialist Senator Bernie Sanders in the US Presidential primary election in 2016" (KOTZ, 2017, p. 4).

24 "Right-wing nationalists have risen to power in Poland, Hungary, Turkey, India, and the Philippines, and even in the United States" (KOTZ, 2017, p. 4).

\section{Referências}

BOWLES, S.; GORDON, D.; WEISSKOPF, T. Beyond the waste land: a democratic alternative to Economic Decline. Nova York: Doubleday, 1984.

Business ascendancy and economic impasse: a structural retrospective on conservative economics, 1979-1986. Journal of Economic Perspectives, American Economic Association, v. 1, n. 3, p. 107-134, 1989.

After the waste land: a democratic economics for the year 2000. Armonk, NY: M. E. Sharpe, 1990.

CHAVANCE, B. Institutional economics. Nova York: Routledge, 2009. 
COUTROT, T. The american radicals: a subversive current at the heart of the empire. In: BIDET, J.; KOUVELAKIS, S. Critical companion to contemporary marxism. Chicago: Haymarket Books, 2009. p. 255-266.

EDWARDS, R.; REICH, M.; WEISSKOPF, T. (Org.). The capitalist system. Englewood Cliffs: Prentice-Hall, 1986.

GORDON, D. Up and down the long roller coaster. In: UNION FOR RADICAL POLITICAL ECONOMICS (Ed.). US capitalism in crisis. Nova York: Union for Radical Political Economics, 1978. p. 22-35.

. Stages of accumulation and long economic cycles. In: WALLERSTEIN, I.; HOPKINS, T. (Ed.). Processes of the world system. Beverly Hills: Sage Publications, 1980. p. 9-45.

. The global economy: new edifice or crumbling foundations? In: KOTZ, D.; MCDONOUGH, T.; REICH, M. (Ed.). Social structures of accumulation: the political economy of growth and crisis. Nova York: Cambridge University Press, 1994. p. 292-305.

GORDON, D.; EDWARDS, R.; REICH, M. Divided works, segmented workers: the historical transformation of labour in the United States. Nova York: Cambridge University Press, 1982.

JESSOP, B.; SUM; N. L. Beyond the regulation approach: putting capitalist economies in their place. Cheltenham: Edward Elgar, 2006.

KOTZ, D. The state, globalization and phases of capitalist development. In: ALBITTRON, R. et al. Phases of capitalist development: booms, crises, and globalizations. Nova York: Palgrave, 2001. p. 93-109.

Institutional structure or social structure of accumulation? In: MCDONOUGH, T. et al. Growth and crisis: social structure of accumulation theory and analysis. National University of Ireland: Galway, 2006. p. 50-58. Disponível em: <http://ssagalway.blogspot.com>. Acesso em: 26 jun. 2017.

KOTZ, D. M. The financial and economic crisis of 2008: a systemic crisis of neoliberal capitalism. Review of Radical Political Economics, v. 41, n. 3, p. 305-317, 2009.

Social structure of accumulation theory, Marxist theory, and system transformation. Review of Radical Political Economics, v. 49, n. 4, p. 1-9, 2017.

KOTZ, D.; MCDONOUGH, T. Global neoliberalism and the contemporary social structure of accumulation. In: MCDONOUGH, T.; REICH, M.; KOTZ, D. Contemporary capitalism and its crises: social structure of accumulation theory for the 21st Century. Nova York: Cambridge University Press, 2010. p. 93-120.

KOTZ, D.; MCDONOUGH, T.; REICH, M. (Ed.). Social structures of accumulation: the political economy of growth and crisis. Nova York: Cambridge University Press, 1994a.

Afterword: new international institutions and renewed world. In: KOTZ, D.; MCDONOUGH, T.; REICH, M. (Ed.). Social structures of accumulation: the political economy of growth and crisis. Nova York: Cambridge University Press, 1994b. p. 307-315.

LEE, F. History of heterodox economics: challenging the mainstream in the twentieth century. Nova York: Routledge, 2009.

LIPPIT, V. Social structure of accumulation theory. In: MCDONOUGH, T.; REICH, M.; KOTZ, D. Contemporary capitalism and its crises: social structure of accumulation theory for the 21st Century. Nova York, Cambridge University Press, 2010. p. 45-71.

Teoria e Evidência Econômica - a. 24, n. 50, p. 26-50, jan./jun. 2018 
LIPPIT, D. V. The neoliberal era and the financial crisis in the light of SSA theory. Review of Radical Political Economics, v. 46, n. 2, p. 1-21, 2014.

MAVROUDEAS, S. Social structures of accumulation, regulation approach and stages theory. In: MCDONOUGH, T. et al. Growth and crises: social structure of accumulation theory and analysis. National University of Ireland: Galway, 2006. p. 200-216. Disponível em: <http:// ssagalway.blogspot.com>. Acesso em: 26 jun. 2017.

MCDONOUGH, T. The construction of social structures of accumulation in US history. In: KOTZ, D.; MCDONOUGH, T.; REICH, M. (Ed.). Social structures of accumulation: the political economy of growth and crisis. Nova York: Cambridge University Press, 1994. p. 101-132.

MCDONOUGH, T.; REICH, M.; KOTZ, D. Contemporary capitalism and its crises: social structure of accumulation theory for the 21st Century. Nova York: Cambridge University Press, 2010.

MCDONOUGH, T. et al. Growth and crisis: social structure of accumulation theory and analysis. National University of Ireland: Galway, 2006. Disponível em: <http://ssagalway.blogspot.com>. Acesso em: 26 jun. 2017.

MELLO FILHO, M. Escola francesa da regulação, escola da estrutura social de acumulação e as etapas do capitalismo. Tese (Doutorado em Economia) $\square$ Universidade Federal de Minas Gerais, Cedeplar, Belo Horizonte, 2016.

O'HARA. P. An institutionalist review of long waves theories: Schumpeterian innovation, modes of regulation and social structures of accumulation. Journal of Economic Issues, v. 28, n. 2, p. 1-21, 1994.

WEISSKOPF, T. The origins and evolution of radical political economics. 25 de setembro de 2012. (Apresentação na conferência "A new insurgency: the Port Huron statement in its time and ours"). Disponível em: <https://sites.lsa.umich.edu/tomweisskopf/2015/08/10/the-originsandevolution-of-radical-political-economics>. Acesso em: 18 out. 2017.

WOLFSON, M. The financial system and the social structure of accumulation. In: KOTZ, D.; MCDONOUGH, T.; REICH, M. (Ed.). Social structures of accumulation: the political economy of growth and crisis. Nova York: Cambridge University Press, 1994. p. 133-145.

WOLFSON, M.; KOTZ, D. A reconceptualization of social structure of accumulation theory. In: MCDONOUGH, T.; REICH, M.; KOTZ, D. Contemporary capitalism and its crises: social structure of accumulation theory for the 21st Century. Nova York: Cambridge University Press, 2010. p. 72-90.

YAN, M.; KOTZ, D.; MCDONOUGH, T. Innovation and development of social structure of accumulation (SSA) theory: a discussion with Lü Shoujun. Social Sciences in China, v. 38, n. 3, p. 127-135, 2017. 